\title{
Synoptic conditions controlling the seasonal onset and days of heatwaves over Korea
}

\author{
Woosuk Choi ${ }^{1}$. Chang-Hoi Ho ${ }^{2}$ D . Jiyoung Jung ${ }^{2} \cdot$ Minhee Chang ${ }^{2} \cdot$ Kyung-Ja Ha ${ }^{3}$
}

Received: 22 September 2020 / Accepted: 16 June 2021 / Published online: 22 July 2021

(c) The Author(s) 2021

\begin{abstract}
As global warming gets worse, the extreme heat exposure time is expected to increase. Considering that the heatwave damages increased by the accumulation of heat stress, it is important to understand the heatwave onset and number of heatwave days (HWDs). Here, we show that the end of East Asian summer monsoon activity (i.e., Changma retreat date, CRD) could be an indicator in determining the onset of the heatwave, and the barotropic structure induced by the circumglobal and Pacific-Japan teleconnections is a key factor in lengthening the number of HWDs in Korea. The onset of the heatwave is delayed when CRD belated than the climatology late over Korea due to sufficient moisture transportation between the edge of western North Pacific subtropical high and cold polar air mass in July. The number of HWDs from July through August over Korea shows a positive linear relationship with the synoptic stagnation index because the upper-layer anticyclone associated with stagnation is formed around Korea by zonal wave activity. Barotropic anticyclone stabilizes the atmosphere and increases the number of clear sky days, which possibly leads to hot days. Fewer HWDs are observed when there is baroclinic instability due to strong upper-level jet stream and synoptic-scale weather systems move smoothly. By identifying the meteorological mechanism of heatwave occurrence and favorable conditions for sustained hot days over Korea, our results are eventually able to contribute to reducing damages caused by heatwaves.
\end{abstract}

Keywords Heatwave Changma retreat $\cdot$ stagnation $\cdot$ heatwave onset $\cdot$ the number of heatwave days

\section{Introduction}

The Korean Peninsula has been recently exposed to an extreme heatwave during summer. In 2018, a strong and long-lasting heatwave with record-breaking surface daily maximum temperature was observed in Korea (Ha et al. 2020, Min et al. 2020). The daily maximum temperature in Seoul, the capital of the Republic of Korea, reached a historical record of $39.6{ }^{\circ} \mathrm{C}$. In Hongcheon, a rural area in Gangwon Province, the daily maximum temperature rose to

Chang-Hoi Ho

hoch@cpl.snu.ac.kr

1 Division of Data Science, University of Suwon, Hwaseong-si, Gyeonggi-do 18323, Republic of Korea

2 School of Earth and Environmental Sciences, Seoul National University, 1 Gwanak-ro, Gwanak-gu, Seoul 08826, Republic of Korea

3 Department of Atmospheric Sciences, Center for Climate Physics, Institute for Basic Science, Pusan National University, Busan 46241, Republic of Korea $41.0^{\circ} \mathrm{C}$, setting a national record. In addition, the national average of the daily maximum temperature of over $33{ }^{\circ} \mathrm{C}$ was recorded for 31.5 days and tropical nights with a daily minimum temperature of over $25^{\circ} \mathrm{C}$, which lasted for 17.7 days. The heatwave caused maximum damage to the vulnerable social group with low financial conditions who cannot afford by using cooling machines (Gasparrini and Armstrong 2011; Zhang et al. 2018). Heatwaves are expected to become a serious problem in the future, being closely associated with global warming (Peng et al. 2011; Lee et al. 2012; IPCC 2014; Kong et al. 2020) and urbanization (Hong et al. 2019).

Potential climatic variations that affect the occurrence of extreme temperatures over East Asia are the following: extension of the western North Pacific subtropical high (WNPSH) and jet stream changes associated with the El Niño-Southern Oscillation (ENSO) and Pacific decadal oscillation (PDO) (Freychet et al. 2018; Liu et al. 2019; Gao et al. 2020; Ho et al. 2021), changes in precipitation due to Indian summer monsoon (ISM) and East Asia summer monsoon (Chen et al. 2019; Lee et al. 2013; Sui et al. 2007; Wu 2017), wave train generation and circulation change due 
to North Pacific sea surface temperature (SST) variability (Ham et al. 2016; Lau et al. 2004; Yoo et al. 2004), westerly intensity change and high pressure stagnation in midlatitude due to Arctic Oscillation (AO) (Gong and Ho 2003; Thompson and Wallace 2000; Wu and Francis 2019), upperlevel anomalous geopotential height by circumglobal teleconnection (CGT) in East Asia (Beverley et al. 2019; Ding and Wang 2005; Lee et al. 2011), diabatic heating over the Indian subcontinent (Kim et al. 2019), and changes in circulation in East Asia due to thermal condition in the Tibetan plateau (Park and Schubert 1997; Duan and Wu 2005; Ha et al. 2012; Wang et al. 2008). Lee and Lee (2016) analyzed the interannual variation in the heatwave frequency in Korea and examined its connection to the large-scale atmospheric circulation. Xu et al. (2019) examined the large-scale circulation anomalies associated with an anomalous anticyclone beginning in July and lasting through August over East Asia. They suggested that wave trains propagate eastward along with the Asian westerly jet in the upper troposphere and affect the heatwave development in Korea.

Most previous studies examined extreme cases of heatwave rather than on a long-term climatic study. For example, Yoo et al. (2004) explained that the atmosphere-ocean coupling over the extratropical Pacific was responsible for the Southeast Asian extreme heatwave in 1994 and compared it to previous (i.e., 1993 year) climatic conditions. They also stated that the western tropical SST explains characteristics of the climate variability over Korea. Min et al. (2014) assessed the possible long-term impacts of increased amounts of greenhouse gas on high summer temperatures in Korea, especially of the 2013 extreme event. Yoon et al. (2018) reported the impacts of topography and soil moisture on heatwaves over the southeastern region of the Republic of Korea in 2015. Yeh et al. (2018) proposed the dynamic processes for the heatwaves of 2016, which occurred due to the anomalous high geopotential height around Mongolia and the Kamchatka Peninsula. Yeo et al. (2019) reported two mechanisms of the heatwave formation in Korea: a zonal wave pattern associated with a large-scale atmospheric wave and a meridional wave pattern associated with convection over the subtropical western North Pacific.

Heatwaves pose an enormous danger to human health (Amengual et al. 2014; Lee and Lee 2016), ecosystems (Beniston et al. 2007), and crop production (Zuo et al. 2015). The characteristics of heatwaves could be influenced by these various mechanisms (Kim et al. 2020). Social damages caused by heatwaves occur when high temperatures continue for a long time rather than sudden shocks of extremely high temperatures. The summertime heatwave day (HWD) is a climatic characteristic, but it shows interannual variations depending on the start date of the heatwave. Therefore, it is important to have an in-depth understanding of the onset and number of HWDs so that potential damages caused by heatwaves could be reduced. The onset of the summertime heatwave in Korea could be determined by the East Asian monsoon activity (Kysely and Kim 2009). In addition, the variability of the HWDs is influenced by the stagnation of the synoptic weather system and regional atmospheric stability. When a barotropic structure is formed due to the WNPSH extension in the lower layer (Choi and Kim 2019), the Pacific-Japan (PJ) teleconnection pattern by tropical convection (Nitta 1987), and changes in the upper geopotential height by the CGT activity (Ding and Wang 2005), it can cause high-impact heatwaves on the surface.

Although both the East Asian summer monsoon activity and barotropic anticyclones affect the initiation and continuation of the heatwave in Korea, there are few studies on the temporal evolution of heatwaves. This study aims to identify the climatic mechanisms of heatwave onset and sustainability by examining the Changma and atmospheric stagnation over the Korean Peninsula. As well as the thermodynamically sufficient conditions of the middle and lower atmosphere, the effects of the upper layer change caused by large-scale teleconnection are evaluated on the seasonal time scale. Understanding how heatwaves start and why they sustain would be profitable information to predict heatwaves and reduce heat-related disease eventually.

The remainder of this paper is organized as follows. Data and methods used in this study are explained in Sect. 2. Section 3 describes the onset of the heatwave. Section 4 presents the information on the HWDs in Korea and largescale variability associated with Changma and atmospheric stagnation, respectively. Concluding remarks are provided in Sect. 5.

\section{Data and methodology}

\subsection{Data}

Daily maximum temperatures from 45 automated synoptic observing system (ASOS) weather stations in Korea were obtained from the Korea Meteorological Administration (KMA) (Fig. 1). These manned observatories provide reliable data subject to the quality control process. In addition, daily geopotential height, zonal and meridional winds, the temperature at $2 \mathrm{~m}$, total precipitation, and specific humidity were obtained from the global atmospheric reanalysis (ERAinterim) produced by the European Centre for MediumRange Weather Forecasts with the $0.75^{\circ} \times 0.75^{\circ}$ horizontal resolution (Dee et al. 2011). All the data were analyzed for the period from 1979 to 2019.

The main climatic factors affecting the formation and evolution of the Changma front over Korea are known as the influx of low-level moisture, expansion of the WNPSH, and the reinforcement of the upper-level jet stream 


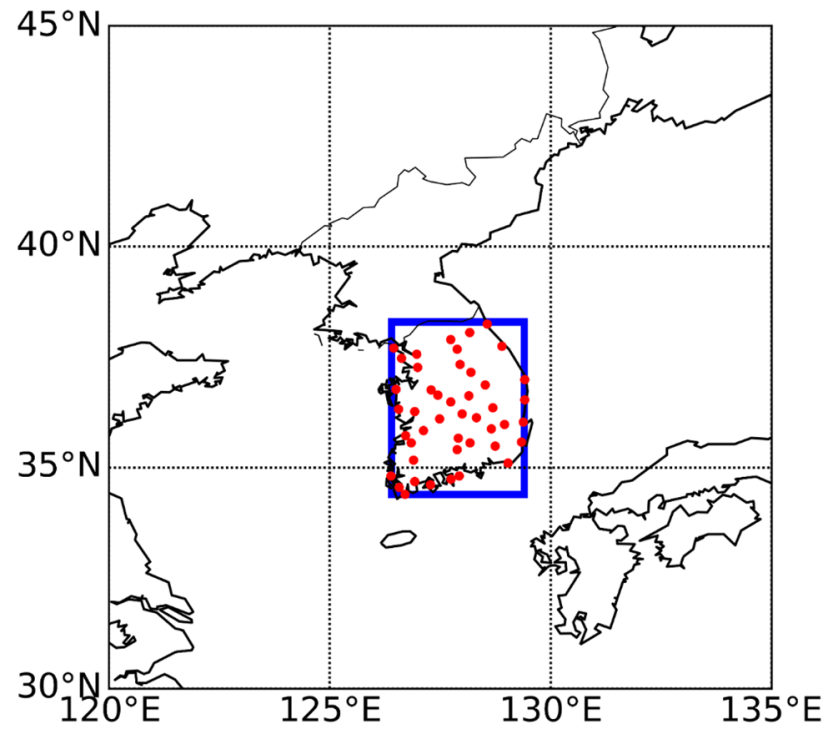

Fig. 1 ERA-interim analysis domain of Korea (blue box, $126.4^{\circ}-$ $129.4^{\circ} \mathrm{E}, 34.4^{\circ}-38.3^{\circ} \mathrm{N}$ ), including 45 automated synoptic observing system stations (red dots)

creating baroclinic instability (KMA 2011). Thus, the end of Changma over Korea is determined through a comprehensive analysis including the low-level moisture flux, ground temperature, location of the rainband front, solar radiation, sunshine time, and wind fields at $200 \mathrm{hPa}$. Information on the annual Changma retreat date (CRD) is provided by the KMA for each station. In this study, the averages of annual CRDs in 45 ASOS weather stations were analyzed.

\subsection{Methodology}

Although many definitions of a heatwave exist in previously published studies, herein, a heatwave was defined by the daily maximum temperature of over $33^{\circ} \mathrm{C}$, in accordance with KMA standard temperature. The annual HWD was calculated as the average of the number of days when the maximum temperature exceeded $33{ }^{\circ} \mathrm{C}$ at each ASOS station (Lee and Lee 2016; Xu et al. 2019; Yeh et al. 2018). The temperature threshold of $33{ }^{\circ} \mathrm{C}$ was adopted by considering its significant mortality impact (Kysely and Kim 2009). The main conclusion of this study is not sensitive to analyzing this threshold using a relative one such as 90 th (i.e., $32.7^{\circ} \mathrm{C}$ ) or 95th (i.e., $33.9^{\circ} \mathrm{C}$ ) (figure not shown). The temperature values averaged over the Korea region were used when analyzing the reanalysis data. The Korea region was defined as the smallest box that contained 45 ASOS stations (Fig. 1).

The CGT phenomenon was proposed by Ding and Wang (2005) and has been known as one of the major modulators of the summertime synoptic weather pattern in the midlatitude region. Because the summertime weather over the Korean Peninsula varies depending on the phase of CGT, the CGT was introduced to understand the heatwave in Korea (Yeh et al. 2018, Choi et al. 2020, Ha et al. 2020). In its original version (Ding and Wang 2005), the CGT index was calculated by the $200-\mathrm{hPa}$ geopotential height average over northwestern India $\left(35^{\circ}-40^{\circ} \mathrm{N}\right.$ and $60^{\circ}-70^{\circ}$ $\mathrm{E})$. Although one of the centers for CGT responses is the eastern China-Korea-Japan region (Beverley et al. 2019), this original CGT index does not directly reflect the anticyclonic anomalies over East Asia, which are predominantly responsible for the favorable condition of the heatwave in Korea. To better represent the upper-level anticyclonic anomalies over Korea, a stagnation index is newly defined in this study by adding the 200 -hPa geopotential height in the East Asia area $\left(30^{\circ}-50^{\circ} \mathrm{N}\right.$ and $\left.110^{\circ}-140^{\circ} \mathrm{E}\right)$ to the aforementioned original CGT index (Beverley et al. 2019). In other words, the stagnation index is calculated by the sum of 200-hPa geopotential height averages over the East Asia box and northwestern India area. The correlation coefficient $(r)$ between this stagnation index and the CGT index is 0.83 , which means the variability of the stagnation index is very similar with the CGT variation at a $99 \%$ confidence level. However, the stagnation index is found to better explain the heatwave over Korea $(r=0.70)$ than the CGT index $(r=0.42)$ during the 1979-2019 period, because the stagnation index more focuses on the series of anticyclones which locates not only over the northwestern India box but also over the Korean Peninsula. In addition, by representing the barotropic structure in Korea, this stagnation index can be considered comprehensively not only the impact of zonal teleconnection but also meridional variation such as PJ pattern.

\section{Impacts of the Changma retreat}

Climatically, the averaged HWD values over Korea are 0.6 days (5\%) in June, 4.2 days (38\%) in July, 5.8 days (54\%) in August, and 0.2 days (2\%) in September. However, the interannual time series of HWD beginning in June and lasting through September shows a large HWD variability from 0 days (1993) to 30 days or more (1994 and 2018) (Fig. 2). Much of this variability is caused by the number of HWDs in July ( $r=0.86)$, associated with the start of the heatwave, as well as HWDs in August ( $r=0.87$ ). The number of HWDs in July depends on the onset of the heatwave, which might be related to CRD (Yoon et al. 2018, Choi et al. 2020). After the Changma period, Korea is predominantly influenced by warm and humid airmass with plentiful insolation. Therefore, the onset of the heatwave is suggested to be determined by CRD, which shows large interannual variability.

The number of HWDs from June through July shows a significant negative relationship with CRD (Fig. 3). Except for the extreme cases of 1994 and 2018, the slope is approximately -1 HWD week ${ }^{-1}$, and the correlation coefficient is 
Fig. 2 The number of annual heatwave days (HWD)s in Korea between 1979 and 2019. Reddish-brown colors indicate the months. The average number of HWDs ( $m=10.9$ days) and one and two standard deviations ( $\sigma=6.9$ days) are shown as horizontal dashed lines

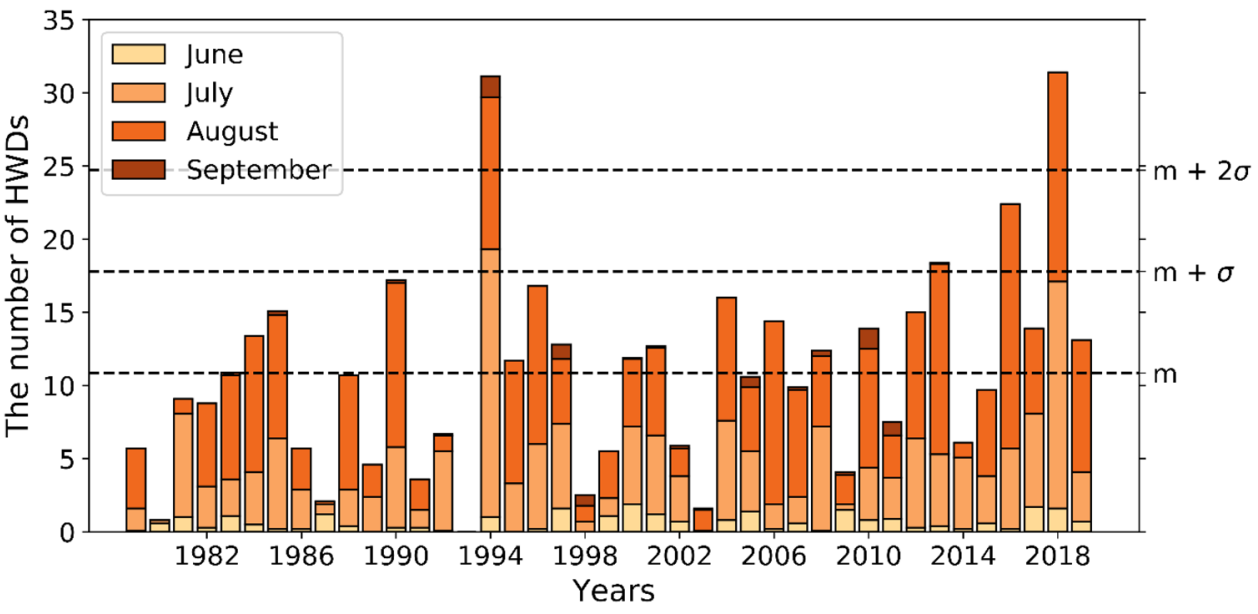

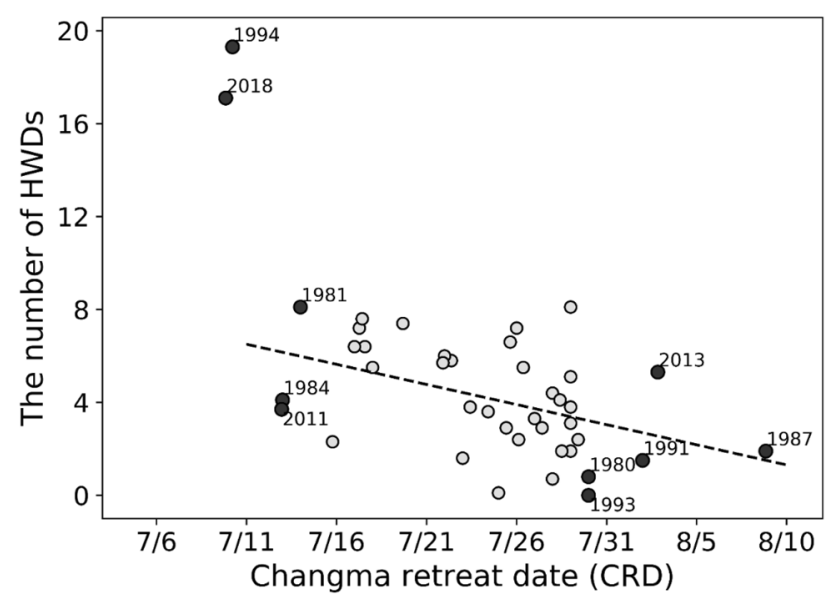

Fig. 3 Scatter plot between Changma retreat date (CRD) and the number of HWDs from June through July between 1979 and 2019. The climatology of CRD is shown for July 23-25. The dashed line shows a linear fitting between CRD and HWDs, except for the years 1994 and 2018

-0.46 in the linear regression analysis, showing a statistically significant relationship of $99 \%$. We compared the large-scale environmental fields collected over 5 years (i.e., 1981, 1984, 1994, 2011, and 2018) with early CRD and other 5 years (i.e., 1980, 1987, 1991, 1993, 2013) with late CRD to identify the differences between two groups. As a result, this analysis is expected to be able to provide characteristics of the early and late CRD years.

The summertime heatwaves frequently occur when strong solar radiation continues in a clear sky and there is less rain event. We examined precipitation and mid-level geopotential height anomaly in July according to the composite analysis by CRD (Fig. 4). The Changma front is formed between a cold polar air mass (represented by $5820 \mathrm{gpm}$, in blue line) and a warm, humid region, which is depicted as the boundary of WNPSH (represented by $5880 \mathrm{gpm}$, in red line) (KMA 2011). In the years when the Changma ended early, the gradient of 500-hPa geopotential height was small and there is little precipitation around the Korean Peninsula in July (Fig. 4a). However, there are more precipitation and a large gradient of 500-hPa geopotential height in the $30^{\circ}-35^{\circ} \mathrm{N}$ during the years when the rainy season ended late (Fig. 4b).

When the Changma front retreats quickly, the polar air mass moves further north than its climatology (Fig. 4c g, $\mathrm{k}$ ), which explains the northward migration of the Changma front. Moreover, when the development of WNPSH is weaker than the climatology, the Changma front is not explicitly formed, and there is relatively little systematic moisture transport to the Korean Peninsula (Fig. 4e, i). In 1994, during the record-breaking heatwave, the amount of precipitation in July was minimal, caused by the early CRD (Fig. 4g). However, Korea was overwhelmingly covered by the expanded WNPSH starting from early summer in 2018 so that clear weather prevailed, and the heatwave occurred (Fig. 4k).

In general, when the WNPSH boundary is expanded further westward than the climatology and moisture is transported to Korea along the WNPSH boundary, much precipitation occurs around Korea. When a meridional geopotential height gradient is large, the baroclinic wave tends to be developed in the vicinity of the boundary between WNPSH and cold air mass (Li 2006; Murakami and Matsumoto 1994). Eventually, it results in stronger frontogenesis (i.e., Changma) and the late onset of the heatwave. As a result, a large amount of precipitation can be seen between the explicitly well-developed WNPSH boundary and the cold air mass in all years (Fig. 4d, f, h, j, 1). In 2013, however, the nation is divided by prolonged time of Changma in the central part as well as heatwaves in the south (Fig. 41), so the number of HWDs in 2013 is higher than 1984 and 2011. Therefore, the CRD would be not a sufficient factor to regulate the number of HWDs. 


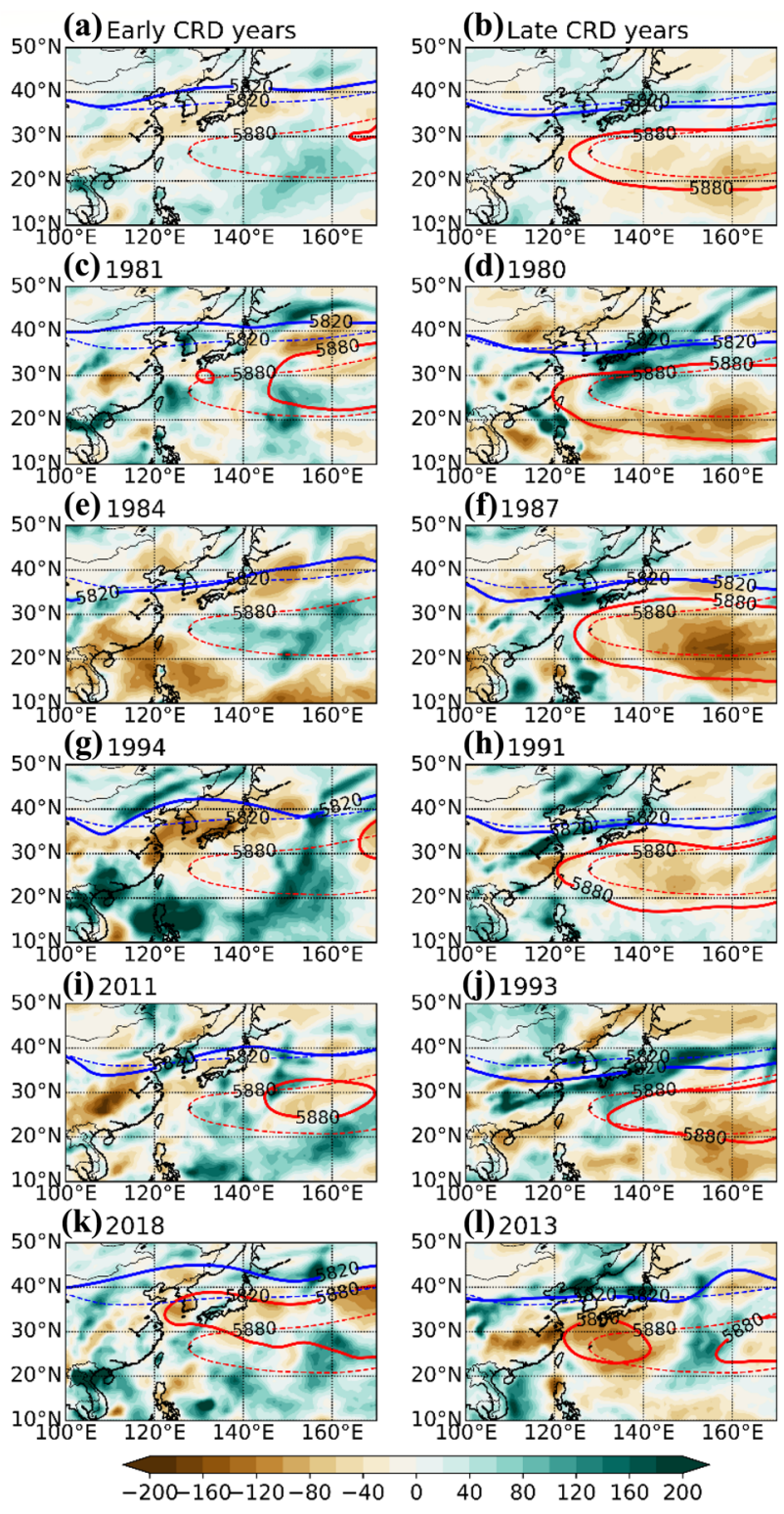

Fig. 4 Precipitation anomaly (shading, $\mathrm{mm} \mathrm{mon}^{-1}$ ) and geopotential height at $5820 \mathrm{~m}$ (blue line) and at $5880 \mathrm{~m}$ (red line) in July. The left panel demonstrates a composite pattern and 5 years of early CRD, whereas the right panel shows late CRD years. Red and blue solid lines show geopotential height in a corresponding year. Dashed lines mean climatological averages

\section{Heatwave days}

In this study, the number of HWDs is analyzed because the high-heat exposure time (i.e., HWDs) is more closely related to the heatwave damage (Laaidi et al. 2012; Mishra et al. 2017; Rey et al. 2009). Heatwave exposure in Korea is strongly related to the variation in the barotropic highpressure system, which makes sustaining the clear sky over Korea. Large-scale climate variabilities such as CGT, PJ pattern, WNPSH, and PDO can induce high pressure around

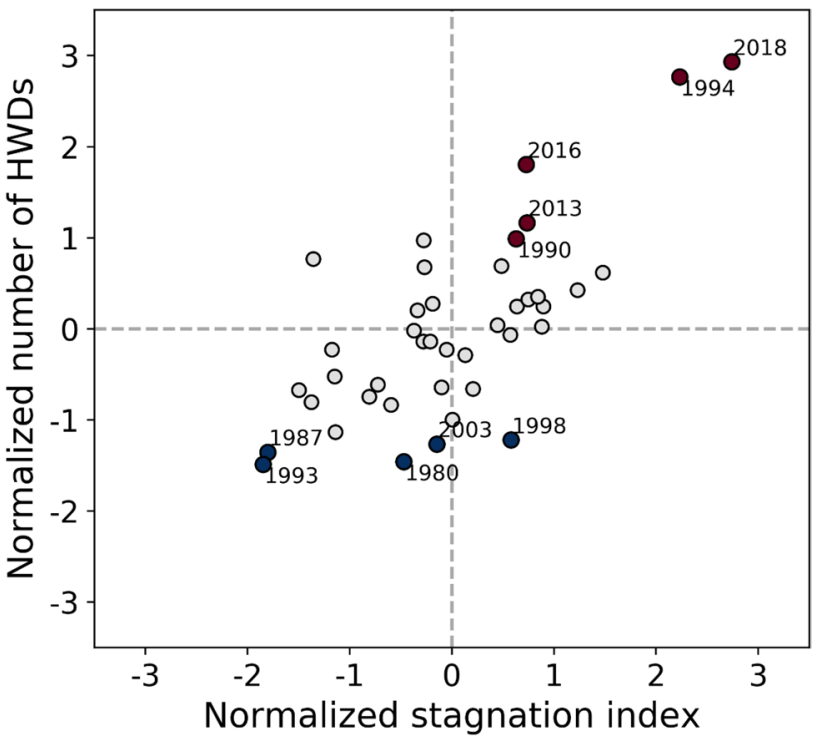

Fig. 5 Scatter plot of the normalized number of HWDs and the atmospheric stagnation index from July through August between 1979 and 2019. The highest and lowest 5 years of the number of HWDs are represented by red and blue dots

Korea and make heatwaves last for a long time (Ding and Wang 2005; Yeo et al. 2019, Choi and Kim 2019; Liu et al. 2019).

A definite positive relationship was identified by analyzing the stagnation index and the number of HWDs. The correlation coefficient is 0.70 which is statistically significant at the $99 \%$ confidence level (Fig. 5). Thus, the number of HWDs in Korea from July through August varies according to the atmospheric stagnation. We compared 5 years with the highest HWDs (i.e., 1990, 1994, 2013, 2016, and 2018) and 5 years with the lowest HWDs (i.e., 1980, 1987, 1993, 1998, and 2003) and examined the effects of stagnation on the heatwave in Korea. These 5 years on the basis of the number of HWDs were different from those 5 years used in the CRD analysis.

The zonal wave trains across the mid-latitudes affect the heatwave formation in Korea by spreading wave energy (Yeo et al. 2019). The barotropic structure tends to be constructed if there are higher 200-hPa geopotential height anomalies in Korea during the summer. Such a position of the barotropic structures slows the eastward-moving weather systems around East Asia and blocks the upper-level trough migration, creating favorable conditions for the prolonged heatwave (Ding and Wang 2005). Normalized 200-hPa zonal and meridional winds over Korea were examined together with HWDs from July through August to establish the relationship between the stagnation of atmospheric flow and heatwaves (Fig. 6). The number of HWDs and zonal wind speed at $200 \mathrm{hPa}$ are closely related, considering that the red dots tend to be located on the left side, whereas the blue 


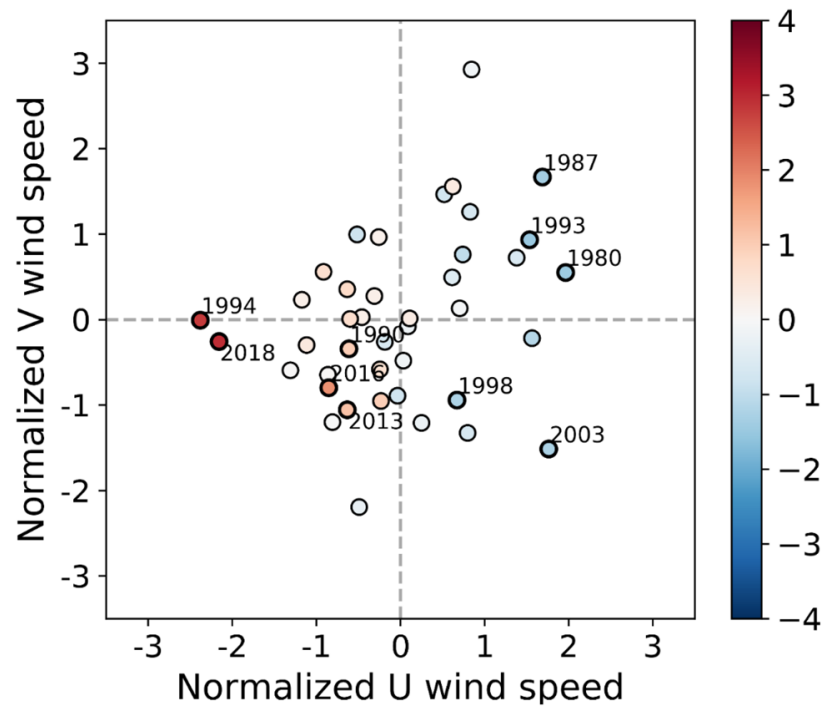

Fig. 6 Scatter plot of the normalized 200-hPa zonal and meridional winds over Korea from July through August. The normalized number of HWDs for each year is represented by blue to red colors. The highest and lowest 5 years of the number of HWDs are represented

dots appear on the right side of the diagram. For 4 years out of five, the low number of HWDs indicated that the zonal wind was stronger than one standard deviation. It means that the weather system was flowing smoothly in that years. The years of the high number of HWDs tend to show weakened upper-level westerly winds, resulting in blocking patterns, clear weather, and lots of HWDs. However, atmospheric stagnation is not the only factor that determines the number of HWDs as it is influenced by various other factors, such as udden local rainfall or horizontal heat advection.

The years with a high number of HWD show a positive geopotential height anomaly at $200 \mathrm{hPa}$ in East Asia (Fig. 7). This positive anomaly over Korea is the result of wave propagation from the upper troposphere in mid-latitude continental Asia and corresponds to a pattern reported in a previous study (Wu 2017). Overall, the atmospheric flow is stagnant, and the weather system is maintained due to the strengthening of the upper-level high pressure around East Asia. During the years of high HWDs, the core of anticyclone in the upper atmosphere is generally located in the northern part of the Korean Peninsula, and its low-level core appears in the southern part of the Korean Peninsula (Fig. 7a). Therefore, the barotropic and stable atmospheric structure is constructed over Korea. The anomalous barotropic high over Korea was observed in August of 1994, 2016, and 2018 (Fig. 7e, i, k), when favorable conditions for the development of the heatwave and led to prolonged sunny weather were created in the East Asian continent. In 1990 and 2013, the barotropic anticyclone anomaly was not noticeable in Korea due to different geopotential height changes in the upper and lower levels. The horizontal and meridional wind
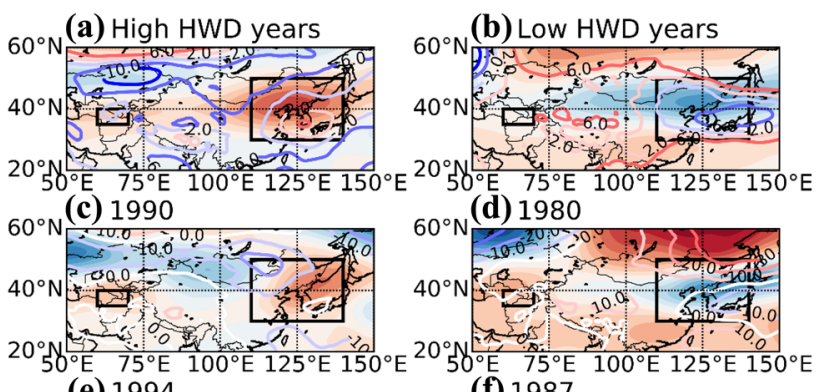

(e) 1994

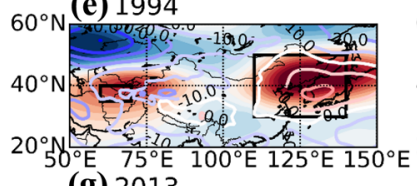

(f) 1987
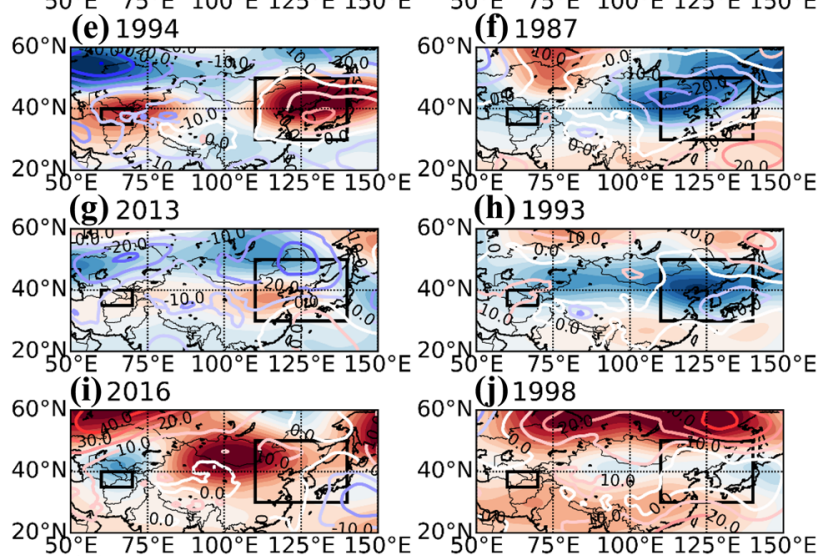

(k) 2018
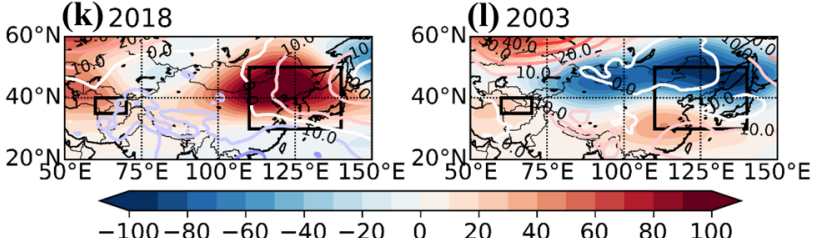

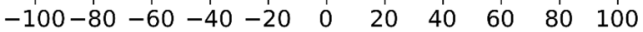

Fig. 7 Geopotential height anomaly at $200 \mathrm{hPa}$ (shading, m) and $850 \mathrm{hPa}$ (contour, m) from July through August. The left panel shows a composite pattern and five years of the highest number of HWDs, whereas the right panel represents the lowest HWD years. Black boxes indicate typical locations for the high geopotential height anomaly regions by CGT, according to Beverley et al. (2019)

velocities are also close to the climatology (close to value ' 0 ' in Fig. 6) in those years. Increases in the number of HWDs in those years are presented by a small number of rainfall events rather than the atmospheric stagnation.

The years with the lowest number of HWD show a negative geopotential height anomaly at $200 \mathrm{hPa}$ over Korea (Fig. 7b). For the 850-hPa geopotential height anomaly, negative geopotential height anomalies were also identified in all low HWD years (Fig. 7d, f, h, j, l). In all 5 years, the anomalous low was located on the northern side of the Korean Peninsula, thus strengthening the upper-level jet stream over Korea. Therefore, the eastward movement of the weather system is activated and makes baroclinic instability over Korea. Various weather phenomena such as cloudy weather or continuous rainfall could occur rather than lasting the clear sky and hot weather.

Anomalies of the $2 \mathrm{~m}$ temperature, $850-\mathrm{hPa}$ wind, and mid-level geopotential height were investigated to 
understand the mechanisms for the 5 years of the highest and lowest HWDs, respectively (Fig. 8). If the barotropic change happens in the geopotential height over Korea due to the atmospheric stagnation, it may interact with neighboring climate systems such as the WNPSH and control summer

(a) High HWD years

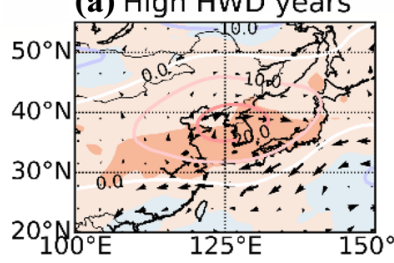

(c) 1990

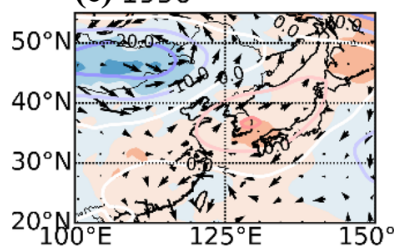

(e) 1994

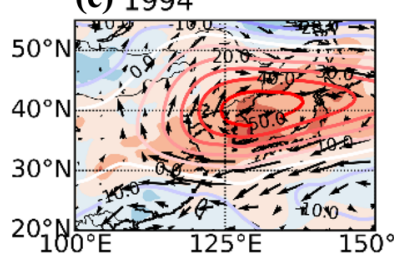

(g) 2013

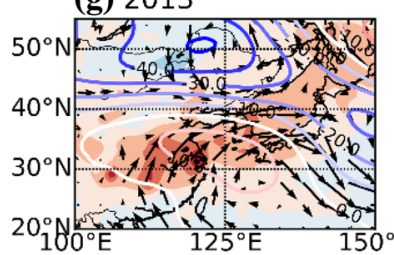

(i) 2016

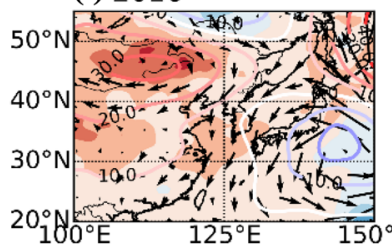

(k) 2018

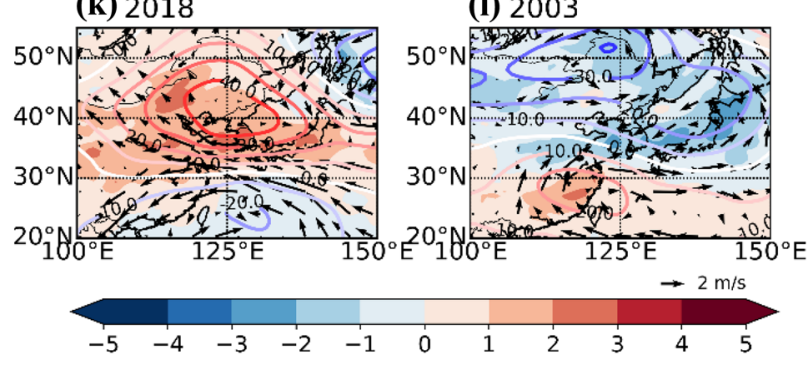

Fig. 8 Anomalies of temperature at $2 \mathrm{~m}$ elevation (shading, K), 850$\mathrm{hPa}$ wind (vectors, $\mathrm{m} \mathrm{s}^{-1}$ ), and the 500-hPa geopotential height (contour, m) from July through August. The left panel shows a composite pattern and five years of the highest number of HWDs, whereas the right panel represents the lowest HWDs years weather in East Asia. The development of an anticyclone over Korea lead to an increase in surface air temperature (i.e., the temperature at $2 \mathrm{~m}$ ), provoke clear skies, and stabilize atmospheric conditions. The low-level anomalous anticyclonic circulations around the Korean Peninsula partially suppress the rainfall events which relieves heatwaves by reducing moisture transport in high HWD years. In the north-south direction, the signs of temperature anomaly and geopotential height between the mid- and low-latitude regions are opposite (Fig. 8a, b). These dipole changes are estimated to be the influence of convection related with the PJ pattern.

In the years of the highest five HWDs, environmental conditions leading to the prolonged HWDs were observed in August with a positive anomaly of the $2 \mathrm{~m}$ temperature in most regions of East Asia, including Korea. The warm anomaly region is generally consistent with the 500 -hPa geopotential height anomaly and has actively induced anticyclonic circulations around Korea. Extreme heatwave cases, 1994, 2016, and 2018, can be classified as the cluster 3, 2, and 1 of heatwaves covering the entire Korean Peninsula as reported in previous studies, respectively (Yoon et al. 2020). However, in the 5 years with the lowest number of HWDs, the negative temperature at $2 \mathrm{~m}$ and geopotential height anomaly were found in Korea. The changes in geopotential height at $500 \mathrm{hPa}$ change were associated with the contraction of the WNPSH boundary. Anomalous wind from the ocean resulted in more moisture transport into Korea and a lower number of HWDs.

\section{Concluding remarks}

Heatwave studies have been mostly focused on understanding extreme cases or the analysis of daily maximum temperature. Many climatic indices, such as the ENSO, PDO, Indian Ocean dipole, ISM, and AO, are used to diagnose statistical relationships with the summertime temperature over East Asia and to understand the mechanism of heatwave development. Although the effects of large-scale climate variability predominantly impact the changes in summer weather in East Asia, it is difficult to investigate extreme daily weather solely using long-term climate variability. The time scale of rain showers caused by atmospheric instability is very short relative to the aforementioned climate variabilities. Moreover, the approaches that rely on the large-scale climate variability limit the understanding of the overall phenomena and reasons, especially with ENSO and AO being predominant over winter.

This study investigated the characteristics of the summer heatwaves by identifying the meteorological factors that control the onset and days of the heatwave. Statistical analysis showed that the onset of the heatwave is related to 
CRD in July, whereas the prolonged heatwave in August is mainly due to the anticyclone over Korea and stagnation of the weather system by the large-scale teleconnections. If climate models well simulate the East Asian monsoon activity such as CRD or the variability of WNPSH in the future, the performance of heatwave prediction on a seasonal time scale will be improved.

The determination of the end date of the heatwave concerning its sustainability is crucial. Notably, interannual variability at the end of the heatwave is negligible. During the past 41 years, most of the heatwaves in Korea consistently ended in late August. However, as global warming continues, the variability in WNPSH and the end of hot summer weather may change. As such, trend monitoring and future studies on the timing of WNPSH weakening in autumn are required. As another issue, although the amplitude of the interannual variability of CRD in the current climate is greater, the long-term trends of CRD changes should also be considered. Further studies on the changes in the Changma activity associated with the position of the jet stream are necessary along with the studies on the jet positional change and various climatic systems. Such studies could ultimately form the basis for the understanding of the heatwave characteristics and heatwave prediction in the future.

Acknowledgements This work was funded by the Korea Meteorological Administration Research and Development Program under Grant [KMI2020-00610].

Open Access This article is licensed under a Creative Commons Attribution 4.0 International License, which permits use, sharing, adaptation, distribution and reproduction in any medium or format, as long as you give appropriate credit to the original author(s) and the source, provide a link to the Creative Commons licence, and indicate if changes were made. The images or other third party material in this article are included in the article's Creative Commons licence, unless indicated otherwise in a credit line to the material. If material is not included in the article's Creative Commons licence and your intended use is not permitted by statutory regulation or exceeds the permitted use, you will need to obtain permission directly from the copyright holder. To view a copy of this licence, visit http://creativecommons.org/licenses/by/4.0/.

\section{References}

Amengual A, Homar V, Romero R, Brooks HE, Ramis C, Gordaliza M, Alonso S (2014) Projections of heat waves with high impact on human health in Europe. Glob Planet Change 119:71-84

Beniston M (2007) Future extreme events in European climate: an exploration of regional climate model projections. Clim Change 81:71-95

Beverley JD, Woolnough SJ, Baker LH, Johnson SJ, Weisheimer A (2019) The northern hemisphere circumglobal teleconnection in a seasonal forecast model and its relationship to European summer forecast skill. Clim Dyn 52:3759-3771

Chen C-A, Hsu H-H, Hong C-C, Chiu P-G, Tu C-Y, Lin S-J, Kitoh A (2019) Seasonal precipitation change in the western North
Pacific and East Asia under global warming in two high-resolution AGCMs. Clim Dyn 53:5583-5605

Choi J-W, Kim H-D, Wang B (2020) Interdecadal variation of Changma (Korean summer monsoon rainy season) retreat date in Korea. Int J Climatol 40:1345-1360

Choi N, Lee M-I, Cha D-H, Lim Y-K, Kim K-M (2020) Decadal changes in the interannual variability of heat waves in East Asia caused by atmospheric teleconnection changes. J Clim 33:1505-1522

Choi W, Kim K-Y (2019) Summertime variability of the western North Pacific subtropical high and its synoptic influences on the East Asian weather. Sci Rep 9:1-9

Dee DP (2011) The ERA-Interim reanalysis: configuration and performance of the data assimilation system. Q J R Meteorol Soc 137:553-597

Ding Q, Wang B (2005) Circumglobal teleconnection in the Northern Hemisphere summer. J Clim 18:3483-3505

Duan A, Wu G (2005) Role of the Tibetan Plateau thermal forcing in the summer climate patterns over subtropical Asia. Clim Dyn 24:793-807

Freychet N, Sparrow S, Tett S, Mineter MJ, Hegerl GC, Wallom D (2018) Impacts of anthropogenic forcings and El Niño on Chinese extreme temperatures. Adv Atmos Sci 35:994-1002

Gao T, Luo M, Lau N-C, Chan TO (2020) Spatially distinct effects of two El Niño types on summer heat extremes in China. Geophys Res Lett 47:e2020GL086982

Gasparrini A, Armstrong B (2011) The impact of heat waves on mortality. Epidemiology 22:68-73

Gong D-Y, Ho C-H (2003) Arctic Oscillation signals in the East Asian summer monsoon. J Geophys Res 108:4066

Ha K-J, Chu J-E, Lee J-Y, Wang B, Hameed SN, Watanabe M (2012) What caused the cool summer over northern Central Asia, East Asia and central North America during 2009? Environ Res Lett 7:044015

Ha K-J (2020) What caused the extraordinarily hot 2018 summer in Korea? J Meteorol Soc Jpn Ser II 98:153-167

Ham Y-G, Kug J-S, Yeh S-W, Kwon M (2016) Impact of two distinct teleconnection patterns induced by western Central Pacific SST anomalies on Korean temperature variability during the early boreal summer. J Clim 29:743-759

Ho C-H, Park C-K, Yun J, Lee E-J, Kim J, Yoo H-D (2021) Asymmetric expansion of summer season on May and September in Korea. Asia-Pac J Atmos Sci 57:619-627

Hong J-W, Hong J, Kwon EE, Yoon DK (2019) Temporal dynamics of urban heat island correlated with the socio-economic development over the past half-century in Seoul, Korea. Environ Pollut 254:112934

IPCC, Pachauri RK, Meyer LA (eds) (2014) Climate Change 2014: Synthesis Report. Contribution of Working Groups I, II and III to the Fifth Assessment Report of the Intergovernmental Panel on Climate Change [Core Writing Team. IPCC, Geneva, p 151

Kim H-K, Moon B-K, Kim M-K, Kwon M (2020) Dynamic mechanisms of summer Korean heat waves simulated in a long-term unforced Community Climate System Model version 3. Atmos Sci Lett 21(7):e973

Kim M-K, Oh J-S, Park C-K, Min S-K, Boo K-O, Kim J-H (2019) Possible impact of the diabatic heating over the Indian subcontinent on heat waves in South Korea. Int J Climatol 39(3):1166-1180

Kong Q, Guerreiro SB, Blenkinsop S, Li X-F, Fowler HJ (2020) Increases in summertime concurrent drought and heatwave in Eastern China. Weather Clim Extremes 28:100242

Korea Meteorological Administration (2011) Changma white book. Korea Meteorological Administration, Seoul 
Kysely J, Kim J (2009) Mortality during heat waves in South Korea, 1991 to 2005: how exceptional was the 1994 heat wave? Clim Res 38:105-116

Laaidi K, Zeghnoun A, Dousset B, Bretin P, Vandentorren S, Giraudet E, Beaudeau P (2012) The impact of heat islands on mortality in Paris during the August 2003 heat wave. Environ Health Perspect 120:254-259

Lau K, Lee J, Kim K, Kang I (2004) The North Pacific as a regulator of summertime climate over Eurasia and North America. J Clim 17:819-833

Lee J-Y (2011) How predictable is the northern hemisphere summer upper-tropospheric circulation? Clim Dyn 37:1189-1203

Lee M-H, Ho C-H, Kim J, Song C-K (2012) Assessment of the changes in extreme vulnerability over East Asia due to global warming. Clim Change 113:301-321

Lee S-S, Seo Y-W, Ha K-J, Jhun J-G (2013) Impact of the western North Pacific subtropical high on the East Asian monsoon precipitation and the Indian Ocean precipitation in the boreal summertime. Asia-Pac J Atmos Sci 49:171-182

Lee WS, Lee MI (2016) Interannual variability of heat waves in South Korea and their connection with large-scale atmospheric circulation patterns. Int J Climatol 36:4815-4830

Lhotka O, Kyselý J (2015) Characterizing joint effects of spatial extent, temperature magnitude and duration of heat waves and cold spells over Central Europe. Int J Climatol 35:1232-1244

Li T (2006) Origin of the summertime synoptic-scale wave train in the western North Pacific. J Atmos Sci 63:1093-1102

Liu Q, Zhou T, Mao H, Fu C (2019) Decadal variations in the relationship between the western Pacific subtropical high and summer heat waves in East China. J Clim 32:1627-1640

Min S-K, Kim Y-H, Kim M-K, Park C (2014) Assessing human contribution to the summer 2013 Korean heat wave. Bull Am Meteorol Soc 95:S48-S51

Min S-K, Kim Y-H, Lee S-M, Sparrow S, Li S, Lott FC, Stott PA (2020) Quantifying human impact on the 2018 summer longest heat wave in South Korea. Bull Am Meteorol Soc 101:S103-S108

Mishra V, Mukherjee S, Kumar R, Stone DA (2017) Heat wave exposure in India in current, $1.5^{\circ} \mathrm{C}$, and $2.0^{\circ} \mathrm{C}$ worlds. Environ Res Lett 12:124012

Murakami T, Matsumoto J (1994) Summer monsoon over the Asian continent and western North Pacific. J Meteorol Soc Jpn Ser II 72:719-745

Nitta T (1987) Convective activities in the tropical western Pacific and their impact on the Northern Hemisphere summer circulation. $\mathrm{J}$ Meteorol Soc Jpn Ser II 65:373-390

Park CK, Schubert SD (1997) On the nature of the 1994 East Asian summer drought. J Clim 10(5):1056-1070

Peng RD, Bobb JF, Tebaldi C, McDaniel L, Bell ML, Dominici F (2011) Toward a quantitative estimate of future heat wave mortality under global climate change. Environ Health Perspect 119:701-706
Rey G, Fouillet A, Bessemoulin P, Frayssinet P, Dufour A, Jougla E, Hémon D (2009) Heat exposure and socio-economic vulnerability as synergistic factors in heat-wave-related mortality. Eur J Epidemiol 24:495-502

Sui CH, Chung PH, Li T (2007) Interannual and interdecadal variability of the summertime western North Pacific subtropical high. Geophys Res Lett 34:L11701

Thompson DW, Wallace JM (2000) Annular modes in the extratropical circulation. Part I: month-to-month variability. J Clim 13:1000-1016

Wang B, Bao Q, Hoskins B, Wu G, Liu Y (2008) Tibetan Plateau warming and precipitation changes in East Asia. Geophys Res Lett 35:L14702

Wu R (2017) Relationship between Indian and East Asian summer rainfall variations. Adv Atmos Sci 34:4-15

Wu B, Francis JA (2019) Summer Arctic cold anomaly dynamically linked to East Asian heat waves. J Clim 32:1137-1150

Xu K (2019) Large-scale circulation anomalies associated with extreme heat in South Korea and Southern-Central Japan. J Clim 32:2747-2759

Yeh S-W, Won Y-J, Hong J-S, Lee K-J, Kwon M, Seo K-H, Ham Y-G (2018) The record-breaking heat wave in 2016 over South Korea and its physical mechanism. Mon Weather Rev 146:1463-1474

Yeo SR, Yeh SW, Lee WS (2019) Two types of heat wave in Korea associated with atmospheric circulation pattern. J Geophys Res Atmos 124:7498-7511

Yoo S-H, Ho C-H, Yang S, Choi H-J, Jhun J-G (2004) Influences of tropical western and extratropical Pacific SST on East and Southeast Asian climate in the summers of 1993-94. J Clim 17:2673-2687

Yoon D, Cha D-H, Lee G, Park C, Lee M-I, Min K-H (2018) Impacts of synoptic and local factors on heat wave events over southeastern region of Korea in 2015. J Geophys Res Atmos 123:12081-12096

Yoon D, Cha D-H, Lee M-I, Min K-H, Kim J, Jun S-Y, Choi Y (2020) Recent changes in heatwave characteristics over Korea. Clim Dyn 55(7):1685-1696

Zhang L, Zhang Z, Ye T, Zhou M, Wang C, Yin P, Hou B (2018) Mortality effects of heat waves vary by age and area: a multi-area study in China. Environ Health 17:54

Zuo J, Pullen S, Palmer J, Bennetts H, Chileshe N, Ma T (2015) Impacts of heat waves and corresponding measures: a review. $\mathrm{J}$ Clean Prod 92:1-12

Publisher's Note Springer Nature remains neutral with regard to jurisdictional claims in published maps and institutional affiliations. 